NOTE: This manuscript has been published in the International Journal of Eating Disorders.

FULL CITATION: Ahuvia, I., Jans, L., \& Schleider, J. (2022). Secondary effects of body dissatisfaction interventions on adolescent depressive symptoms: A metaanalysis. International Journal of Eating Disorders, 55(2), 231- 246.

https://doi.org/10.1002/eat.23659

\title{
Secondary Effects of Body Dissatisfaction Interventions on Adolescent Depressive Symptoms: A Meta-Analysis
}

\author{
Isaac Ahuvia ${ }^{1}$, Laura Jans ${ }^{1}$, Jessica Schleider ${ }^{1}$ \\ ${ }^{1}$ Stony Brook University
}


BD Intervention Effects on Depression

Data availability statement. Data may be accessed, alongside analytic code and pre-analytic plan, at https://osf.io/734n8/.

Acknowledgements. The authors would like to thank Dr. Melissa Atkinson, Dr. Helen Sharpe, Dr. Eric Stice, and Dr. Simon Wilksch for providing data for this study that were not otherwise available.

Conflicts of interest. JLS receives grant support from the National Institutes of Health (DP5OD28123), the Klingenstein Third Generation Foundation, the American Psychological Foundation, the Society for Clinical Child and Adolescent Psychology, Limbix, Inc, and the Upswing Fund for Adolescent Mental Health. JLS has co-authored and receives royalties from sales of a therapeutic workbook for adolescents, published by New Harbinger, and is under contract with Oxford University Press to co-edit a book on low-intensity mental health interventions for youth. JLS is on the Scientific Advisory Board for Walden Wise, Inc. The authors report no other conflicts.

Funding sources. The authors have no funding sources to report for this study. 


\begin{abstract}
Objective: Depression is a leading cause of disability among adolescents, yet existing treatments are variably effective, suggesting needs to identify novel intervention targets. Body dissatisfaction (BD) may be a promising, but understudied, target: BD is common among adolescents; prospectively associated with future depression; and modifiable through intervention. BD interventions are typically evaluated in terms of impacts on eating disorders, but many trials also measure depression-related secondary outcomes. However, BD intervention effects on depression have not been systematically examined. We therefore conducted a meta-analysis to estimate secondary effects of BD interventions on depression symptoms and related outcomes in adolescents (ages 12-19). Method: Our systematic review included RCTs published between January 2006-December 2020. Across-group effect sizes were analyzed using robust variance estimation. Pre-registered methods, data, and analytic code are available at https://osf.io/734n8/. Results: The meta-analysis included thirteen RCTs, 50 effect sizes, and 6,962 participants. BD interventions led to significant post-intervention reductions in depression-related outcomes versus control conditions ( $g=-.19$ at postintervention, $95 \% \mathrm{Cl}-.07,-.31, p=.005)$. No evidence emerged for moderators of this metaanalytic effect. Discussion: Overall, BD-focused interventions significantly reduced adolescent depression, with mean post-intervention effect sizes comparable to those observed for interventions targeting depression explicitly. Results are bolstered by pre-registered methods and robustness checks. Limitations include a lack of data on participants' sexual and gender identities and a significant risk of bias in the underlying literature. Future research on BD interventions should measure depression symptom severity as a secondary outcome.
\end{abstract}

Keywords: body dissatisfaction, body image, depression, negative affect, meta-analysis 


\section{Introduction}

Depressive symptoms and disorders reflect a cluster of widespread and debilitating mental health problems that often onset and worsen during adolescence (Kessler et al., 2003). They are associated with a host of adverse psychological and physical health outcomes (Copeland et al., 2021), are linked to decreased academic achievement (Clayborne et al., 2019), and are major risk factors for suicide (Brådvik, 2018). Despite the widespread prevalence of depressive symptoms and disorders in adolescence, attempts to treat and prevent adolescent depression are inconsistently effective. A meta-analysis of psychotherapy for depression in children and adolescents (mean participant age 14-18) found a mean effect size of $g=-.29$, significantly inferior to the mean effect sizes of psychotherapy for other disorders (Weisz et al., 2017). Depression prevention interventions have netted significant but small preventive effects on depressive symptoms in youth, with meta-analyses of youth-focused depression prevention programs finding small overall effects at post-intervention ( $d=-.11$ to $d=-.33$ ) and negligible-tosmall effects at various follow-up points ( $d=.07$ to $d=-.22$ ) (Horowitz \& Garber, 2006; Stice, Shaw, et al., 2009; Stockings et al., 2016; Werner-Seidler et al., 2017). As such, there is a clear need to identify novel, promising targets for adolescent depression interventions, particularly those that may hold potential to treat and/or prevent depression in girls.

Body dissatisfaction (BD) may be one such target. Body dissatisfaction is defined as negative subjective evaluations of one's physical body, such as one's figure or weight (Stice \& Shaw, 2002). There is a strong theoretical basis linking BD to depression, particularly in adolescents. In the "body-dissatisfaction-driven hypothesis," BD leads to depressive symptoms both directly and indirectly (Sharpe et al., 2018; Stice \& Bearman, 2001). Body dissatisfaction leads to depressive symptoms directly because appearance is a major facet of one's self-concept. Body dissatisfaction also leads to depressive symptoms indirectly, through dieting and bulimic 
symptoms; dieting may lead to depression as (a) failures to achieve dietary goals lead to emotional distress and (b) caloric deprivation adversely affects mood, and bulimic symptoms may lead to depression because of the shame and guilt associated with them. The backdrop for this relationship is sociocultural pressures to meet unrealistic body ideals, which drive BD in the first place, as described by the "sociocultural theory" of BD (Stice, 1994).

Empirical research supports these theories. Body dissatisfaction predicts depression in adolescence above and beyond the predictive effects of other risk factors for depression (Bearman \& Stice, 2008). Prospective studies of adolescents have found BD to explain approximately $40 \%$ of the variance of depressive symptoms at 1 -year follow-up (Murray et al., 2018), approximately $7 \%$ of the variance in depressive symptoms at 3-year follow-up (Stice \& Bearman, 2001), and approximately $5 \%$ of the variance in depressive symptoms at 5-year follow-up (in girls only; Paxton et al., 2006). Body dissatisfaction prospectively predicts depressive symptoms in both boys and girls (Ferreiro et al., 2014; Johnson \& Wardle, 2005; Murray et al., 2018; Stice et al., 2000; Stice \& Bearman, 2001). One recent large-scale longitudinal study found that BD at 14 predicted mild and severe depressive episodes at 18 in both boys and girls, with ORs from 1.50 to 2.85 (Bornioli et al., 2020).

This evidence suggests that body dissatisfaction may be an important target for depression interventions, particularly those aiming to treat and/or prevent depression in adolescents. However, existing depression prevention programs rarely target BD directly, instead favoring more universal cognitive-behavioral targets such as problem-solving skills and cognitive restructuring (Gillham \& Chaplin, 2011; Stice, Shaw, et al., 2009). Body dissatisfaction-focused interventions are common, however, in the field of eating disorder prevention. 
Body Dissatisfaction Interventions for Eating Disorders. Many eating disorder (ED) prevention interventions target BD (Stice \& Shaw, 2004); however, the literature around these interventions has tended not to focus on the potential impacts of their BD interventions on depression. To date, very few interventions have explicitly targeted both BD and depression. One such trial of a 4-session, clinician-delivered CBT intervention targeting BD found substantial effects on both BD (d=-.67) and depression $(d=-.52)$ at post-intervention (Bearman et al., 2003); however, despite these promising effects, more recent interventions have not maintained this dual focus on both BD and depression outcomes of eating disorder programs.

Some trials have measured depression symptoms as a secondary outcome of ED interventions-but these trials have not contextualized their depression-related outcomes within the broader depression prevention literature, leading researchers to incorrectly assume the effects of these interventions are relatively small. One such study found effects on depression that are quite substantial within the context of depression prevention ( $d=-.39$ and $d=-.44$ for the two interventions studied). While both effects are larger than meta-analytic effect estimates for depression prevention programs, the authors discussed these effects in the limitation section, stating that "effects for the depression outcome were small, suggesting that the interventions may be most useful for addressing body image and eating-related outcomes" (Chithambo \& Huey, 2017). This framing is emblematic of how depression-related outcomes are discussed in the broader ED prevention literature: depression and the related construct of negative affect are primarily discussed in terms of the risk they convey for $E D$, rather than as important outcomes in their own rights. 


\section{BD Intervention Effects on Depression}

Previous reviews have investigated the effects of certain types of ED interventions on depression-related constructs. One review investigated the effects of indicated prevention interventions on comorbid eating disorder and depressive symptoms (Rodgers \& Paxton, 2014). However, this review excluded universal prevention approaches, and did not feature participants under 14 years-old. There is a strong theoretical rationale, outlined above, for examining the effects of these interventions among a wide range of adolescents, including those under 14 or those who have not yet developed clinically significant risk. Another review investigated the effects of dissonance-based ED prevention programs on negative affect, among other outcomes (Stice et al., 2019). However, this review was not inclusive of all types of BD interventions, nor did it include depression symptom outcomes.

Present Study. Despite the well-established relevance of body dissatisfaction (BD) to the onset of depressive symptoms in adolescence, few trials of BD interventions ${ }^{1}$ have focused on the effects of these interventions on depression. Instead, such trials have highlighted effects on eating disorders, with depressive symptoms and negative affect framed as secondary, noncritical outcomes. In order to gauge BD's promise as an intervention target for preventing adolescent depression, there is a need to systematically characterize the effects of BD-focused interventions on depressive symptoms and disorders. Thus, this systematic review examined whether existing interventions targeting BD might hold promise as a means of preventing or reducing adolescent depression.

\footnotetext{
${ }^{1}$ We use the term "body dissatisfaction interventions" to refer to interventions targeting not only body dissatisfaction but also the related risk factors of objectified body consciousness, thin-ideal internalization, and body image concerns more broadly.
} 


\section{Methods}

All study procedures, as well as the coding manual used for data extraction, were pre-registered with Prospero (https://www.crd.york.ac.uk/prospero/display record.php?ID=CRD42021232394) and the Open Science Framework (OSF; https://osf.io/734n8/). Reproducible code and data can be found in a GitHub repository linked within the OSF page.

Search strategy. We conducted searches in multiple bibliographic databases (APA Psyclnfo, ERIC, MEDLINE with Full Text, and OpenDissertations) to identify both peer-reviewed studies and unpublished dissertations evaluating body dissatisfaction interventions. We searched English language articles only. Search terms included "body dissatisfaction," "body image," "eating disorder," and many more; the full syntax for our search including all search terms is included in Appendix X. In addition, we reached out to researchers conducting work on eating disorder prevention in order to maximize the exhaustiveness of our search; one eligible study that did not appear in our database search was identified in this way.

Inclusion and exclusion criteria. Search dates were inclusive of scientific papers published between January 2006 and December 2020. January 2006 was selected as a start date because of the rise in usage of social networking sites that occurred during the mid-2000s; by 2006, nearly half of U.S. adults aged 18-29 reported using at least one social media site (Social Media Fact Sheet, 2021). Because social media use is thought to have influenced cultural and individual attitudes towards body image and disordered eating behaviors (Holland \& Tiggemann, 2016), and because broad internet access among youth has dramatically shaped the design and availability of novel psychosocial interventions, we focused our review on trials published since this date. 


\section{BD Intervention Effects on Depression}

To qualify for inclusion in our meta-analysis, studies needed to have a minimum participant age of at least 10 years old and a maximum age of no more than 19 years old. Our pre-registration specified a maximum age of 18 years; we increased this by one to allow for the inclusion of a pair of evaluations with youth aged 14-19 (Stice et al., 2006; Stice, Rohde, et al., 2009). We excluded interventions administered in post-secondary school settings (e.g., colleges and universities) in order to retain a focus on interventions for early and middle adolescents. We applied no further exclusion criteria based on gender, race, or any other demographic variable. We did not require studies to include only individuals with clinically significant levels of body dissatisfaction or depression, as we were interested in the effects of prevention interventions as well as those of treatment interventions. Studies could be included regardless of the country in which it took place, so long as the article was available in English.

We focused our meta-analysis on reported results of randomized controlled trials (RCTs); studies with non-randomized control groups were excluded. Clustered RCTs, in which the level of randomization (e.g., classroom) is different from the level of analysis (study participants), were included; we coded and report on the number of randomized units across studies. All RCTs had to include an inactive or psychoeducation-only control condition (e.g., waitlist, notreatment, psychoeducation only), such that non-inferiority trials comparing two active interventions were excluded. In addition, studies had to include as an intervention outcome at least one youth-reported, continuous measure of depressive symptom severity or a depressionrelated construct (e.g., trait negative affect; a full list of constructs is available in the preregistered codebook). Means and standard deviations (or other statistics that allowed us to calculate the mean and standard deviation) had to be available at pre- and post-intervention for both the treatment and control group. When necessary data were unreported for studies that 


\section{BD Intervention Effects on Depression}

otherwise met inclusion criteria, we requested the missing information from corresponding manuscript authors.

We limited our focus to psychosocial intervention trials, excluding any medication-oriented trials. We included trials in which a parent was the direct recipient of the intervention, so long as the intervention targeted body dissatisfaction in the child. As parent-directed interventions can be effective ways of addressing mental health problems in children, we felt that including such interventions was appropriate. However, the outcomes of these trials had to be self-reported by the child themselves, as parents may not have adequate insight into their children's mental health to report on it accurately (De Los Reyes \& Kazdin, 2005). To maintain our focus on body dissatisfaction related intervention trials, we included RCTs that tested one or more psychosocial interventions designed to target one of the following factors implicated in restrictive eating disorders and depression: body dissatisfaction, thin-ideal internalization, objectified body consciousness, dieting/diet culture, body image, and/or body acceptance.

Data extraction. Studies meeting inclusion criteria were coded for study and sample characteristics, intervention procedures, and outcomes. All articles were independently coded according to our codebook by IA and LJ. Because both researchers coded every study, interrater reliability (IRR) was calculated on the full sample of coded studies. IRR was calculated as Cohen's $k$ for categorical data and as the intra-class correlation coefficient (ICC) for continuous data. When IRR was below .8, coders met to clarify any ambiguity in the codebook and fields were re-coded until IRR was above .8. Regardless of IRR, all disagreements were resolved through discussion and collaborative article review when necessary. The full codebook, along with as the final dataset of all study characteristics and outcomes, is available on OSF (https://osf.io/734n8/). 
Study-level codes included study year, study country, publication status (peer-reviewed vs. not peer-reviewed), and the presence of participant compensation (present versus absent). We coded the source of each study's sample (community sample, outpatient therapy sample, inpatient therapy sample, or other), the presence of risk screening and screening criteria (body dissatisfaction, eating disorder symptoms, depressive symptoms, or other), and whether the study was opt-in (e.g., participants responded to flyers) or opt-out (e.g., everybody in participating schools was expected to participate, unless they explicitly declined). We coded the type of intervention in four categories: treatment (targeting those experiencing clinicallysignificant problems, based on formal diagnostic assessment), indicated prevention (targeting those demonstrating elevated individual risk factors, but sub-clinical problems), selective prevention (targeting subgroups of the general population who are at higher risk for a target problem, e.g. girls), and universal prevention (targeting the population at large). We coded one variable that was not included in our pre-registered codebook: the recipient of the intervention (youth vs. parent). Additionally, we coded the following sample characteristics: age (mean, minimum, and maximum age), gender (percent female), ${ }^{2}$ ethnicity (percent White, Black, Latino, Asian, Native American, other, and multiple ethnicities, when reported), and sexual minority status (percent sexual minority, when reported). Lastly, we coded the following study-level quality indicators: masked assignment to treatment condition and follow-up data availability (calculated using sample sizes at each time point). For all codes but two, IRR values for studylevel codes ranged from .80 to 1.00 . In the case of (a) percent multiple ethnicities and (b) blind assignment, IRR was less than .8 due to an artifact of the statistical procedure despite only one disagreement between coders for each variable.

\footnotetext{
${ }^{2}$ None of the included studies reported gender separately from sex
} 


\section{BD Intervention Effects on Depression}

Outcome measures were coded according to measure respondent (youth, parent, clinician, or other) and depression-related construct (depression symptoms, trait negative affect, etc.; all included studies measured only depression symptoms or trait negative affect). Inter-rater agreement values for outcome-level codes were both 1.00 .

Group-level codes include whether the group was treatment or control and number of participants assigned to the group. Due to the prevalence of clustered RCTs in our sample, we coded one variable that was not included in our pre-registered codebook: the number of randomized units (e.g., classrooms, schools) per group. Treatment groups were coded for the number of participants who started treatment, the number who completed treatment, treatment completion rate, intervention delivery format (self-administered, group, individual, digital/online, or other), and provider type (self-administered, clinician-administered, lay-administered, or other). We additionally coded treatment length in terms of minutes, sessions, and days. Control groups were coded for control condition (waitlist/no treatment, psychoeducation, placebo, or

other). Lastly, we coded the following group-level quality indicators: the presence of a treatment manual, the public availability of the treatment manual, the presence of pre-intervention facilitator training, and the presence of facilitator supervision. For all codes but three, IRR values for study-level codes ranged from .82 to 1.00 . In the case of (a) pre-intervention facilitator training and (b) intervention delivery format, IRR was less than .8 due to an artifact of the statistical procedure despite only one disagreement between coders for each variable. A third code, intervention target, did not fit neatly into codable categories due to the wide, overlapping range of targeted constructs among interventions. As a result, we recorded intervention targets idiographically, based on each author's written summary of the target and contents of the intervention at hand, and did not include this variable as a moderator. 


\section{BD Intervention Effects on Depression}

Additionally, we recorded group-level outcomes for treatment and control groups at preintervention, post-intervention, first follow-up (when available), and final follow-up (when available). At each time point we recorded group $n$, mean, and standard deviation; for the follow-up outcomes, we also coded follow-up length (less than 3 weeks post-treatment, between 3-12 weeks post-treatment, and greater than 12 weeks post-treatment). Where studies collected data on more than one continuous depression-related outcome, we include effects from each outcome. In the case of one study, statistics were reported by group and by gender (Diedrichs et al., 2015); we collapsed statistics across subgroups by taking weighted means of outcomes and pooling standard deviations. In the case of four studies (Atkinson \& Wade, 2015; Stice, Rohde, et al., 2009; Wilksch et al., 2015; Wilksch \& Wade, 2009), statistics were not included in the published manuscript and were collected via email with the corresponding authors.

Analysis. For each treatment-control comparison we calculated Hedge's g effect size (Hedges, 1981) at post-intervention and at each follow-up time-point where depression-related outcome measure was reported. Hedge's $g$ is a standardized effect size expressed in units of standard deviations. It is similar to Cohen's $d$, but features a minor correction that reduces the upward bias Cohen's $d$ displays in small sample sizes. As per our pre-registration, we calculated effect sizes as the standardized difference between the treatment group's mean and the control group's mean. We provide both (a) an estimate of the overall effect size at post-intervention, and (b) an estimate of the overall effect size at follow-up. In both cases, our analysis utilized a correlated effects model with robust variance estimation (Hedges et al., 2010) to account for the fact that effect sizes from the same study are not independent.

As a robustness check, we also estimated effect sizes based on both pre- and post-intervention data (reflecting relative change in outcomes of interest across intervention and control groups). 


\section{BD Intervention Effects on Depression}

For these estimates, we calculated Hedge's $g$ as the difference between the treatment group's mean pre-post difference and the control group's mean pre-post difference. We used the same method when calculating follow-up effects. Because we only included RCTs, each study should on average be balanced on pre-intervention variables, and so given sufficiently large sample sizes, we will find the same effects using both pre- and post-intervention data as when we use only post-intervention data. In practice however, RCTs in this area are rarely large enough to ensure pre-intervention balance on all variables, and so there may be minor differences in the effect sizes yielded by these methods.

We included all depression-related outcomes in our meta-analysis regardless of the construct measured (namely, depression symptom severity or trait negative affect [NA]). Although depression symptom severity and NA are considered to be distinct constructs, they are tightly linked and their high correlation has been documented in samples at-risk for eating disorders $(r$ $=.62-.76$, see Amaral et al., 2019; Bearman et al., 2003). Additionally, we analyzed outcome type (depression symptom severity versus NA) as a possible moderator of intervention effects.

Data cleaning and analysis was conducted in R (v3.6.2; R Core Team, 2019). We estimated meta-analytic correlated-effects models using robust variance estimation with small-sample correction (Hedges et al., 2010) using the R package robumeta (v2.0; Fisher et al., 2017). Correlated-effects models are one of two commonly used methods that allow for the inclusion of multiple, dependent effect sizes from studies, the other method being multilevel mixed-effects models (for a comparison, see López-López et al., 2018). Both methods result in unbiased estimates of the fixed effects and their standard errors (Moeyaert et al., 2017). As a robustness check, we also estimated multilevel mixed-effects versions of our models (where effects are clustered within studies) using the R package metafor (v2.4; Viechtbauer, 2010). 
We additionally conducted moderator tests with the coded variables to determine if study effects differed significantly by these study and group characteristics. To optimize reliability of subgroup estimates, we do not include any categories with fewer than 3 studies in these analyses. For each categorical moderator, we provide both (a) subgroup analyses estimating the metaanalytic mean using only studies belonging to a certain subgroup and (b) t-tests for the significance of the variable when included as a moderator in the overall model (no categorical moderator included more than two levels with $\geq 3$ studies, meaning each moderator was represented by only one coefficient and could be analyzed with a t-test). For each continuous moderator, we report the value of the coefficient as well as a t-test of the significance of the variable when included as a moderator in the overall model.

Risk of bias. We produced a funnel plot of observed effects by effects' standard errors, and additionally conducted an Egger's test by regressing each normalized effect estimate (estimate divided by its standard error) against its precision (reciprocal of the standard error of the estimate) and testing the significance of the intercept (Egger et al., 1997). This regression was conducted with the same mixed-effects model framework described above. In addition, we coded study quality indicators (detailed above) employed in previous systematic reviews of psychosocial RCTs (Lipsey \& Wilson, 2001; Weisz et al., 2017) and tested them as moderators. These included two study-level quality indicators (masked assignment and follow-up data availability) and four group-level quality indicators (presence of a treatment manual, manual availability, facilitator training, facilitator supervision).

\section{Results}


Study selection. Our systematic search netted 1,458 citations. Upon initial (title and abstract) review, 1,410 were excluded (258 were duplicates, 1,152 did not meet study criteria). Fortyeight manuscripts were extracted for full-text review to determine eligibility for inclusion. Upon further review, 35 of these studies did not meet inclusion criteria; reasons for exclusion (nonmutually exclusive) can be found in Figure 1. A total of 13 studies, which included 21 postintervention effect sizes and 29 follow-up effect sizes for program effects on depression symptoms or negative affect, met all inclusion criteria (total $N=6,962$ ).

[Figure 1 goes about here]

Characteristics of included studies. Of the 13 studies, 12 were published in peer-reviewed journals ( 1 was an unpublished dissertation) and 5 were conducted in the United States (8 were conducted elsewhere). The average study sample was $85 \%$ female (range: $50 \%-100 \%$ ) and had a mean participant age of 14 years old (range: $12-17$ years old). Racial and ethnic breakdowns are challenging to report, as included studies reported a variety of different categories (and many did not report any at all). Among studies that reported race/ethnicity, the average sample was $82 \%$ White. Among the six studies that reported Black identity, the average study sample was 3\% Black; among the six studies that reported Hispanic identity, the average study sample was $25 \%$ Hispanic; among the seven studies that reported Asian identity, the average study sample was $5 \%$ Asian; no other racial/ethnic category was reported in more than two studies. The average study sample was $18 \%$ non-White (range: $5 \%-42 \%$ ), which is the summary variable used for moderation analysis. Notably, no studies reported on participants' sexual identity or sexual minority status, and no studies differentiated between participants' biological sex and gender identity. Seven of the thirteen studies were indicated prevention trials, such that participants qualified for participation if they endorsed elevations in pre-intervention 


\section{BD Intervention Effects on Depression}

body dissatisfaction or, in the case of one study, if they reported either body image or eating problems. One trial tested a selective prevention intervention, where participants were selected not by individual-level risk factors but by their belonging to an at-risk group (in this case, the trial included exclusively girls, who are at higher risk of developing eating disorders than boys). The remaining five studies were universal trials (i.e., adolescents could participate regardless of preintervention characteristics). When studies selected participants based on risk factors, these factors were always risk factors for eating disorders; no intervention targeted participants based on depression symptoms or risk factors. All but one trial featured a community- or school-based sample.

With regards to study outcomes, eight studies collected outcome data on trait negative affect and six collected outcome data on depression symptom severity (one trial measured both). Trait negative affect was measured using variations of the Positive and Negative Affect Schedule (PANAS; Watson \& Clark, 1994), whereas depression symptom severity was measured with the Patient Health Questionnaire-9 in one trial (PHQ-9; Kroenke et al., 2001), the Beck Depression Inventory-Short Form in one trial (BDI-SF; Beck \& Beck, 1972), the Child Depression Inventory and the Child Depression Inventory-Short Form in three trials (CDI and CDI-SF; Kovacs \& Preiss, 1992), and the Center for Epidemiologic Studies Depression Scale in one trial (CES-D; Radloff, 1977). All negative affect and depression outcome measures were youth self-report assessments (as opposed to clinician- or parent-report).

Of the 18 active interventions evaluated in the 13 included trials (some trials included two active intervention conditions), the vast majority were clinician-administered $(n=14)$ by a single provider to small groups $(n=16)$. Fifteen of the 18 interventions were designed for delivery directly to young people, and three were delivered to parents or caregivers. The average 
intervention duration was five sessions (range: 1-34), with an average of 321 minutes (range: 30-1530) and 32 days from start to finish (range: 1-238). The average intervention completion rate, reported for only 11 of the 18 intervention groups, was $82 \%$. Of the 14 control conditions in the 13 included intervention trials, 11 were waitlist/no-treatment controls, two featured psychoeducation, and one featured expressive writing. Only one study included in the full-text screening stage was excluded on the basis of comparing two active interventions; this study compared different components of a media literacy intervention to one another (Wilksch et al., 2006). Across both intervention and control groups the average per-group sample size was 213 at pre-intervention (range: 23-1,020), 188 at post-intervention (range: 15-842), and 182 at follow-up (range: 17-728).

Select study characteristics are detailed in Table 1. All coded study characteristics are available in our publicly available dataset, which can be found at https://osf.io/734n8/.

[Table 1 goes about here]

\section{Representative interventions}

Trials of The Body Project and Media Smart appear multiple times among our included studies. The Body Project and its adaptations (Amaral et al., 2019; Atkinson \& Wade, 2015; Linville et al., 2015; Stice et al., 2006; Stice, Rohde, et al., 2009) are interventions that seek to prevent the onset of eating disorders by reducing thin-ideal internalization. The intervention spends relatively little time on psychoeducation, instead engaging groups of participants in activities that challenge the thin-ideal. Activities and homework assignments (e.g., writing about the downsides of pressure to be thin, verbally critiquing the thin-ideal) are designed to be counter- 
attitudinal, eliciting cognitive dissonance for participants who have internalized thin-ideal beliefs. This dissonance subsequently prompts participants to reevaluate and reduce their own pursuit of the thin-ideal (Stice, Rohde, et al., 2009).

Media Smart (Wilksch et al., 2006; Wilksch et al., 2015) consists of eight lessons designed to increase media literacy and help participants resist internalizing harmful body-related messages in the media. Lessons are interactive and cover a variety of topics including stereotypes portrayed in the media, techniques advertisers use to digitally alter images, and consumer activism. Participants discuss the pressure to be thin or muscular, engage in role-plays where they practice responding to negative comments from family or peers, and send emails to advertisers about their messages (Wilksch et al., 2006; Wilksch et al., 2015).

\section{Overall post-intervention effects of body dissatisfaction interventions on youth depression-related outcomes.}

A correlated-effects model with robust variance estimation tested the overall effect of body dissatisfaction $(\mathrm{BD})$ interventions compared with control conditions across 21 post-intervention treatment-control comparisons (13 studies). BD interventions were associated with significant reductions in depression-related outcomes at post-intervention relative to controls, with an estimated meta-analytic effect size of $g=-.19(95 \% \mathrm{Cl}-.07,-.31, p=.005)$. When examining depression symptom severity and trait negative affect outcomes separately, estimates were $g=$ -.17 for the effect of BD interventions on depression symptom severity $(95 \% \mathrm{Cl} .03,-.36, p=$ $.075)$ and -.26 for the effect of $\mathrm{BD}$ interventions on trait negative affect $(95 \% \mathrm{Cl}-.03,-.49, p=$ .030), relative to controls. The estimated effect heterogeneity statistics suggested significant 
between-study variance, as $P^{2}=58 \%$ of total variation in these estimates was due to heterogeneity between studies (Higgins \& Thompson, 2002).

Alternate methods for calculating the post-intervention effect estimate of BD interventions on depression-related outcomes yielded similar results, pointing to a robust estimate in the initial model. Different values for the within-study effect-size correlation, $\rho$, did not result in different estimates (estimates were $g=-.19$ for all values of $\rho$ ). A separate correlated effects model, which used youth self-reported outcomes from both pre- and post-intervention to compute effects of BD interventions relative to controls, yielded an estimated post-intervention effect size of $g=-.18(95 \% \mathrm{Cl}-.08,-.27, p=.003)$. Multilevel mixed-effects models found post-intervention effect size estimates of $g=-.21(95 \% \mathrm{Cl}-.09,-.33, p=.002)$ when using only post-intervention data to compute intervention effect sizes, and $-.19(95 \% \mathrm{Cl}-.10,-.27, p<.001)$ when using preand post-intervention data to compute intervention effect sizes.

[Figure 2 goes about here]

\section{Moderators of post-intervention effects of body dissatisfaction interventions on youth depression-related outcomes.}

Detailed moderation results are presented in Table 2. As per our pre-registration, we conducted moderation analyses only when each subgroup included $n \geq 3$ studies. As a result, some variables or variable levels could not be reliably analyzed as moderators, either due to a lack of available data or lack of variability. Among these were sample source (only one study did not feature a community sample), control condition type (only two studies featured a 
psychoeducation control, and only one featured a control categorized as "other"3), and delivery format (only two studies tested an intervention designed for individual, rather than group-based, delivery). Of variables that were tested as moderators, none explained statistically significant variability in post-intervention effects on depression-related outcomes.

[Table 2 goes about here]

\section{Overall follow-up effects of body dissatisfaction interventions on youth depression- related outcomes.}

A correlated-effects model with robust variance estimation tested the overall effect of body dissatisfaction interventions compared with control conditions across 29 follow-up treatmentcontrol comparisons (10 studies), with "follow-up" intervention effects defined as those based on data collected subsequent to an immediate post-intervention assessment. The estimated metaanalytic effect of BD interventions on depression-related outcomes at follow-up (here, between 4 weeks and 2.5 years following the initial post-intervention assessment), relative to controls, was $g=-.04(95 \% \mathrm{Cl} .02,-.11, p=.136)$, which was not statistically significant. When examining depression symptom severity and trait negative affect outcomes separately, estimates were $g=$ -.04 for the effect of $\mathrm{BD}$ interventions on depression symptom severity $(95 \% \mathrm{Cl} .08,-.17, p=$ $.307)$ and $g=-.06$ for the effect of BD interventions on trait negative affect $(95 \% \mathrm{Cl} .09,-.22, p=$ .324), relative to controls. The estimated effect heterogeneity statistics suggested relatively little between-study variance, as $P^{2}=10 \%$ of total variation in the estimates was due to heterogeneity between studies.

\footnotetext{
${ }^{3}$ As an exploratory test we collapsed these two categories into a single category, "psychoeducation or other," so that this subgroup would meet our requirement of $n \geq 3$ studies. However, the result of this moderator test was not statistically significant.
} 
Alternate methods for calculating the follow-up effect estimate of BD interventions on depression-related outcomes yielded similar results, pointing to a robust estimate in the initial model. Different values for the within-study effect-size correlation, $\rho$, did not result in different estimates (estimates were $g=-.04$ for all values of $\rho$ ). A separate correlated effects model, which used youth self-reported outcomes from both pre-intervention and follow-up to compute effects of BD interventions relative to controls, yielded an estimated follow-up effect size of $g=-$ $.06(95 \% \mathrm{Cl} .00,-.12, p=.052)$. Multilevel mixed-effects models found follow-up effect size estimates of $g=-.06(95 \% \mathrm{Cl}-.01,-.12, p=.029)$ when using only follow-up data to compute intervention effect sizes, and $g=-.07(95 \% \mathrm{Cl}-.03,-.12, p=.003)$ when using pre-intervention and follow-up data to compute intervention effect sizes.

[Figure 3 goes about here]

\section{Moderators of follow-up effects of body dissatisfaction interventions on youth depression-related outcomes.}

Detailed moderation results are presented in Table 3. As per our pre-registration, we only included subgroups with $n \geq 3$ studies. As a result, some variables or variable levels could not be analyzed as moderators due to a lack of data or lack of variability. Of variables that were tested as moderators, none were statistically significant predictors of the overall follow-up effect size estimate.

[Table 3 goes about here] 


\section{Study quality and publication bias.}

An Egger's test of the post-intervention effect sizes was statistically significant $(p=.009)$, indicating a pattern consistent with publication bias. As indicated in the funnel plot (Figure 4), Hedge's $g$ effect sizes tended to be larger (as in, further from zero) for less precise estimates of post-intervention effects (i.e., studies with smaller sample sizes). At follow-up, an Egger's test did not indicate a statistically significant relationship between effect sizes and their standard errors $(p=.193)$. This pattern is presented in Figure 5. With regards to study quality variables, none were statistically significant moderators at either post-intervention or follow-up.

[Figure 4 goes about here]

[Figure 5 goes about here]

\section{Discussion}

Depressive symptoms and disorders are widespread and debilitating (Kessler et al., 2003), commonly emerge during adolescence, and have consequences for both the psychological and physical health of those affected (Copeland et al., 2021). Despite this, interventions that seek to prevent and/or treat depression in adolescence are inconsistently effective, with meta-analytic effect sizes in the small range at post-intervention and in the negligible-to-small range at various follow-up points (Horowitz \& Garber, 2006; Stice, Shaw, et al., 2009; Stockings et al., 2016; Werner-Seidler et al., 2017). Body dissatisfaction (BD) may be a useful target for efforts to prevent or treat depression in adolescence, since it is (a) common in this developmental stage (Wang et al., 2019), (b) prospectively associated with the emergence of depression symptoms 
(Bearman \& Stice, 2008), and (c) modifiable through intervention (Stice \& Shaw, 2004). While interventions targeting depression in adolescence tend not to focus on $\mathrm{BD}$, many interventions targeting eating disorders in adolescence do (Stice \& Shaw, 2004); in addition, many of these interventions also measure depression-related outcomes. Leveraging this literature, we conducted a meta-analysis to estimate the effect of BD interventions on depression symptomatology and related outcomes.

Across 13 randomized trials, 50 effect sizes, and 6,962 total participants, we found that interventions targeting body dissatisfaction have effects on adolescent depression that are largely comparable to the effects of interventions that explicitly target depression. At post-test, we found an average effect size of $g=-.19$, which is squarely within the range found by metaanalyses of depression prevention and treatment programs for this age group (for prevention, $d$ $=-.11$ to $d=-.33$; for treatment, $g=.29$; Horowitz \& Garber, 2006; Stice, Shaw, et al., 2009; Stockings et al., 2016; Weisz et al., 2017; Werner-Seidler et al., 2017). At follow-up, we found an average effect size of $g=-.04$, which was negligible in size and not statistically significant. While this indicates that the effects of BD interventions on depression wane over time, this too is in line with effects of interventions that target depression explicitly.

The reliability of these findings is supported by this study's adherence to open science principles including pre-registered methodology, a publicly available dataset, and reproducible analytic code which formed the basis of all results reported in this manuscript. Methods were registered with Prospero and the Open Science Framework, and data and code are hosted in a Github repository; for the sake of convenience, all of these resources are available in a single webpage: https://osf.io/734n8/. 
Limitations. Through moderator tests we hoped to identify characteristics of trials that were associated with larger effect sizes, including participant characteristics, intervention format, and control conditions. However, none of these tests yielded statistically significant moderators. This may reflect a lack of variability among included studies, a lack of eligible studies generally, and/or a lack of true effects of our moderator variables. This represents one major limitation of the present study: perhaps due to a lack of statistical power owing to limitations in our sample, we were unable to draw strong conclusions about what characteristics of trials were associated with larger or smaller effects. As the body of literature grows, moderator analyses will become more practical.

Another important limitation of the research summarized in this meta-analysis is a lack of data on participants' sexual and gender minority status. Although the trials included in this analysis reported on gender, none distinguished between gender identity and sex assigned at birth. Furthermore, no trial reported on participants' sexual identities. This is noteworthy because sexual and gender minority youth are at higher risk for both body dissatisfaction and depression (Borgogna et al., 2018; Goldhammer et al., 2019). Future studies should collect data on diverse sexual and gender identities and examine these variables as potential moderators of intervention effects.

Of the studies included in this meta-analysis, samples were overwhelmingly White $(82 \%$ on average) and female ( $85 \%$ on average). This is problematic, as the relationship between BD and depression may operate differently across different racial/ethnic groups (Franko \& StriegelMoore, 2002) and genders (Bearman \& Stice, 2008). This speaks to the need for more research on $\mathrm{BD}$ and depression in diverse populations. As this body of research grows, it will become 


\section{BD Intervention Effects on Depression}

more practical to investigate differences in how BD interventions affect depression across groups.

An important caveat to our findings is the risk of bias present in the meta-analytic estimate of BD intervention effects. We found a significant, positive relationship between each effect size's magnitude and its standard error. This is consistent with a pattern of publication bias, whereby studies finding small or insignificant effects are less likely to be published, and thus underrepresented in this meta-analysis. Another possible explanation for this relationship is a pattern whereby trials with indicated populations featured both smaller samples and larger effects, whereas universal prevention interventions had both larger samples and smaller effects. While we found this pattern to hold descriptively, moderator analyses by intervention type (universal versus indicated) were non-significant. Thus, no strong statistical support emerged for this explanation. Regardless, this significant risk of bias indicates a skewed literature to date, with less precise intervention effect estimates tending to be larger and more precise effect estimates tending to be smaller. This pattern is consistent with the literature on youth psychotherapy generally, where effect sizes from smaller studies tend to be larger (Weisz et al., 2017). Moving ahead, BD intervention researchers might prioritize larger- $\mathrm{N}$ evaluations of indicated prevention trials.

Future research. Our findings offer lessons for the eating disorder field, specifically research conducted on body dissatisfaction interventions. Future trials of BD interventions should include measures of depression symptom outcomes, and researchers in this area might clearly relate BD interventions' impacts on depression-related outcomes to those observed within existing, 


\section{BD Intervention Effects on Depression}

depression-focused interventions for youth. Indeed, even small effects on depression produced by BD interventions are notable, given the small average effects found by treatments for adolescent depression and the importance of even small effects for depression symptoms on a population level (Götz et al., 2021). Future trials should not assume that if a BD intervention has smaller effects on depression than on other outcomes (e.g., eating disorder pathology) that the effects on depression are small or negligible relative to other depression interventions. In fact, present results demonstrate that interventions targeting BD (even without targeting depression explicitly) have comparable effects to those targeting depression.

Likewise, researchers developing and evaluating interventions for adolescent depression might look to BD as a potential intervention target. Body dissatisfaction is highly prevalent (Wang et al., 2019), is a strong predictor of the development of depression (Bearman \& Stice, 2008), and is modifiable through intervention (Stice \& Shaw, 2004). As this meta-analysis suggests, interventions targeting BD appear to have effects on depression that are within-range, on average, to those of interventions targeting depression explicitly (with the caveat that we found substantial risk of bias in this literature). Creating interventions that target BD as a means of preventing/treating depression may not only be effective for depression, but have the added promise of having synergistic effects on eating disorder pathology. To date, very few interventions explicitly target both pathologies by targeting BD (Bearman et al., 2003). New interventions should be developed and evaluated that take aim at both eating disorders and depression by targeting BD.

Further research should also be conducted into what components of depression, specifically, are susceptible to change via BD interventions. Depression symptoms are multifaceted and individuals can meet criteria for major depressive disorder in numerous ways (227, to be exact; 
Zimmerman et al., 2015). It is possible that certain symptoms are more affected by BD interventions than others. For instance, BD interventions may be particularly effective when it comes to the affective symptoms of depression, given the link between BD and negative affect (see "Dual Pathway Model”; Stice \& Van Ryzin, 2019). Body dissatisfaction interventions may also have large effects on appetite-related symptoms, given the relationship between body image and dieting (Stice \& Van Ryzin, 2019). Future research should investigate which components of depression and/or which groups of individuals with depression benefit most from BD interventions.

Interventions that target depression through BD may have the added benefit of intervening in the gender gap in depression that emerges during adolescence. Adolescent girls are more than two times as likely to have depression than adolescent boys, and this pattern remains into adulthood (Kuehner, 2017; NIMH, 2019; Nolen-Hoeksema \& Girgus, 1994; Salk et al., 2017). However, relatively few interventions target factors that are particularly relevant for girls, despite girls being disproportionately likely to experience depression (Gillham \& Chaplin, 2011). The higher rate of $\mathrm{BD}$ among adolescent girls relative to boys has been shown to contribute to the disparity in rates of depression symptoms and diagnoses (Ferreiro et al., 2014; Hyde et al., 2008; Morken et al., 2019). Therefore, interventions targeting depression by way of body dissatisfaction could prove useful in combating the gender gap in depression. Future trials of BD interventions should report effects on depression by gender, and discuss these results within the context of the gender gap in depression.

Conclusion. This study investigated the secondary effects of body dissatisfaction interventions, traditionally designed to prevent the onset of eating disorders, on depression symptoms. Our results indicate that the average effect of interventions targeting $\mathrm{BD}$ on depression symptoms is 
BD Intervention Effects on Depression

comparable to the average effect of interventions targeting depression on depression symptoms. These results are bolstered by this study's pre-registered methods and the utilization of a variety of meta-analytic methods to test the robustness of our estimates. However, conclusions are limited by a lack of significant moderator tests and by a risk of bias present in the underlying literature. Previous research has linked body dissatisfaction to the development of depression symptoms (e.g., Bearman \& Stice, 2008; this study demonstrates that body dissatisfaction interventions may have the potential to reduce or prevent these symptoms as well. Future research should therefore pay closer attention to the promise of BD interventions for treating and/or preventing depression in adolescents. 


\section{References}

Amaral, A. C. S., Stice, E., \& Ferreira, M. E. C. (2019). A controlled trial of a dissonance-based eating disorders prevention program with Brazilian girls. Psicologia, Reflexao E Critica : Revista Semestral Do Departamento de Psicologia Da UFRGS, 32(1), 13.

Atkinson, M. J., \& Wade, T. D. (2015). Mindfulness-based prevention for eating disorders: A school-based cluster randomized controlled study. The International Journal of Eating Disorders, 48(7), 1024-1037.

Bearman, S. K., \& Stice, E. (2008). Testing a gender additive model: the role of body image in adolescent depression. Journal of Abnormal Child Psychology, 36(8), 1251-1263.

Bearman, S. K., Stice, E., \& Chase, A. (2003). Evaluation of an intervention targeting both depressive and bulimic pathology: A randomized prevention trial. Behavior Therapy, 34(3), 277-293.

Beck, A. T., \& Beck, R. W. (1972). Screening depressed patients in family practice. A rapid technic. Postgraduate Medicine, 52(6), 81-85.

Borgogna, N. C., McDermott, R. C., Aita, S. L., \& Kridel, M. M. (2018). Anxiety and Depression Across Gender and Sexual Minorities: Implications for Transgender, Gender Nonconforming, Pansexual, Demisexual, Asexual, Queer, and Questioning Individuals. Psychology of Sexual Orientation and Gender Diversity, 6(1). https://doi.org/10.1037/sgd0000306

Bornioli, A., Lewis-Smith, H., Slater, A., \& Bray, I. (2020). Body dissatisfaction predicts the onset of depression among adolescent females and males: a prospective study. Journal of Epidemiology and Community Health. https://doi.org/10.1136/jech-2019-213033

Brådvik, L. (2018). Suicide Risk and Mental Disorders. International Journal of Environmental Research and Public Health, 15(9). https://doi.org/10.3390/ijerph15092028 Chithambo, T. P., \& Huey, S. J., Jr. (2017). Internet-delivered eating disorder prevention: A 
BD Intervention Effects on Depression

randomized controlled trial of dissonance-based and cognitive-behavioral interventions. The International Journal of Eating Disorders, 50(10), 1142-1151.

Clayborne, Z. M., Varin, M., \& Colman, I. (2019). Systematic Review and Meta-Analysis:

Adolescent Depression and Long-Term Psychosocial Outcomes. Journal of the American Academy of Child and Adolescent Psychiatry, 58(1), 72-79.

Copeland, W. E., Alaie, I., Jonsson, U., \& Shanahan, L. (2021). Associations of Childhood and Adolescent Depression With Adult Psychiatric and Functional Outcomes. In Journal of the American Academy of Child \& Adolescent Psychiatry (Vol. 60, Issue 5, pp. 604-611). https://doi.org/10.1016/j.jaac.2020.07.895

De Los Reyes, A., \& Kazdin, A. E. (2005). Informant discrepancies in the assessment of childhood psychopathology: a critical review, theoretical framework, and recommendations for further study. Psychological Bulletin, 131(4), 483-509.

Diedrichs, P. C., Atkinson, M. J., Steer, R. J., Garbett, K. M., Rumsey, N., \& Halliwell, E. (2015). Effectiveness of a brief school-based body image intervention "Dove Confident Me: Single Session" when delivered by teachers and researchers: Results from a cluster randomised controlled trial. Behaviour Research and Therapy, 74, 94-104.

Diedrichs, P. C., Atkinson, M. J., Garbett, K. M., Williamson, H., Halliwell, E., Rumsey, N., Leckie, G., Sibley, C. G., \& Barlow, F. K. (2016). Randomized controlled trial of an online mother-daughter body image and well-being intervention. Health Psychology: Official Journal of the Division of Health Psychology, American Psychological Association, 35(9), $996-1006$.

Eickman, L., Betts, J., Pollack, L., Bozsik, F., Beauchamp, M., \& Lundgren, J. (2018). Randomized controlled trial of REbeL: A peer education program to promote positive body image, healthy eating behavior, and empowerment in teens. Eating Disorders, 26(2), 127142. 
Egger, M., Davey Smith, G., Schneider, M., \& Minder, C. (1997). Bias in meta-analysis detected by a simple, graphical test. BMJ , 315(7109), 629-634.

Ferreiro, F., Seoane, G., \& Senra, C. (2014). Toward understanding the role of body dissatisfaction in the gender differences in depressive symptoms and disordered eating: A longitudinal study during adolescence. Journal of Adolescence, 37(1), 73-84.

Fisher, Z., Tipton, E., \& Zhipeng, H. (2017). robumeta: Robust Variance Meta-Regression. https://CRAN.R-project.org/package=robumeta

Franko, D. L., \& Striegel-Moore, R. H. (2002). The role of body dissatisfaction as a risk factor for depression in adolescent girls: are the differences Black and White? Journal of Psychosomatic Research, 53(5), 975-983.

Gillham, J. E., \& Chaplin, T. M. (2011). Preventing girls' depression during the transition to adolescence. Depression in Adolescent Girls: Science and Prevention., 353, 275-317.

Goldhammer, H. B., Maston, E. D., \& Keuroghlian, A. S. (2019). Addressing Eating Disorders and Body Dissatisfaction in Sexual and Gender Minority Youth. American Journal of Preventive Medicine, 56(2), 318-322.

Götz, F. M., Gosling, S. D., \& Rentfrow, P. J. (2021). Small Effects: The Indispensable Foundation for a Cumulative Psychological Science. Perspectives on Psychological Science: A Journal of the Association for Psychological Science, 1745691620984483.

Gumz, A., Weigel, A., Daubmann, A., Wegscheider, K., Romer, G., \& Löwe, B. (2017). Efficacy of a prevention program for eating disorders in schools: a cluster-randomized controlled trial. BMC Psychiatry, 17(1), 293.

Hedges, L. V. (1981). Distribution Theory for Glass's Estimator of Effect size and Related Estimators. Journal of Educational and Behavioral Statistics: A Quarterly Publication Sponsored by the American Educational Research Association and the American Statistical Association, 6(2), 107-128. 
BD Intervention Effects on Depression

Hedges, L. V., Tipton, E., \& Johnson, M. C. (2010). Robust variance estimation in metaregression with dependent effect size estimates. Research Synthesis Methods, 1(1), 3965.

Heinicke, B. E., Paxton, S. J., McLean, S. A., \& Wertheim, E. H. (2007). Internet-delivered targeted group intervention for body dissatisfaction and disordered eating in adolescent girls: a randomized controlled trial. Journal of Abnormal Child Psychology, 35(3), 379-391.

Higgins, J. P. T., \& Thompson, S. G. (2002). Quantifying heterogeneity in a meta-analysis. Statistics in Medicine, 21(11), 1539-1558.

Holland, G., \& Tiggemann, M. (2016). A systematic review of the impact of the use of social networking sites on body image and disordered eating outcomes. Body Image, 17, 100110.

Horowitz, J. L., \& Garber, J. (2006). The prevention of depressive symptoms in children and adolescents: A meta-analytic review. Journal of Consulting and Clinical Psychology, 74(3), 401-415.

Hyde, J. S., Mezulis, A. H., \& Abramson, L. Y. (2008). The ABCs of depression: integrating affective, biological, and cognitive models to explain the emergence of the gender difference in depression. Psychological Review, 115(2), 291-313.

Johnson, F., \& Wardle, J. (2005). Dietary restraint, body dissatisfaction, and psychological distress: a prospective analysis. Journal of Abnormal Psychology, 114(1), 119-125.

Kessler, R. C., Berglund, P., Demler, O., Jin, R., Koretz, D., Merikangas, K. R., Rush, A. J., Walters, E. E., Wang, P. S., \& National Comorbidity Survey Replication. (2003). The epidemiology of major depressive disorder: results from the National Comorbidity Survey Replication (NCS-R). JAMA: The Journal of the American Medical Association, 289(23), 3095-3105.

Kovacs, M., \& Preiss, M. (1992). CDI. Children's Depression Inventory. New York: Multi-Health 
BD Intervention Effects on Depression

Systems.

http://www.pearsonclinical.co.uk/Psychology/generic/ChildrensDepressionlnventory(CDI)/R esources/Technical.pdf

Kroenke, K., Spitzer, R. L., \& Williams, J. B. (2001). The PHQ-9: validity of a brief depression severity measure. Journal of General Internal Medicine, 16(9), 606-613.

Kuehner, C. (2017). Why is depression more common among women than among men? The Lancet. Psychiatry, 4(2), 146-158.

Linville, D., Cobb, E., Lenee-Bluhm, T., López-Zerón, G., Gau, J. M., \& Stice, E. (2015). Effectiveness of an eating disorder preventative intervention in primary care medical settings. Behaviour Research and Therapy, 75, 32-39.

Lipsey, M. W., \& Wilson, D. B. (2001). Practical meta-analysis. Applied Social Research Methods Series; Vol 49., 247. https://psycnet.apa.org/fulltext/2000-16602-000.pdf

López-López, J. A., Page, M. J., Lipsey, M. W., \& Higgins, J. P. T. (2018). Dealing with effect size multiplicity in systematic reviews and meta-analyses. Research Synthesis Methods. https://doi.org/10.1002/jrsm.1310

Moeyaert, M., Ugille, M., Natasha Beretvas, S., Ferron, J., Bunuan, R., \& Van den Noortgate, W. (2017). Methods for dealing with multiple outcomes in meta-analysis: a comparison between averaging effect sizes, robust variance estimation and multilevel meta-analysis. International Journal of Social Research Methodology, 20(6), 559-572.

Morken, I. S., Røysamb, E., Nilsen, W., \& Karevold, E. B. (2019). Body dissatisfaction and depressive symptoms on the threshold to adolescence: examining gender differences in depressive symptoms and the impact of social support. The Journal of Early Adolescence, 39(6), 814-838.

Murray, K., Rieger, E., \& Byrne, D. (2018). Body image predictors of depressive symptoms in adolescence. Journal of Adolescence, 69, 130-139. 
BD Intervention Effects on Depression

NIMH. (2019, February). Major Depression. https://www.nimh.nih.gov/health/statistics/majordepression

Nolen-Hoeksema, S., \& Girgus, J. S. (1994). The emergence of gender differences in depression during adolescence. Psychological Bulletin, 115(3), 424-443.

Paxton, S. J., Neumark-Sztainer, D., Hannan, P. J., \& Eisenberg, M. E. (2006). Body dissatisfaction prospectively predicts depressive mood and low self-esteem in adolescent girls and boys. Journal of Clinical Child and Adolescent Psychology: The Official Journal for the Society of Clinical Child and Adolescent Psychology, American Psychological Association, Division 53, 35(4), 539-549.

Radloff, L. S. (1977). The CES-D Scale: A Self-Report Depression Scale for Research in the General Population. Applied Psychological Measurement, 1(3), 385-401.

R Core Team. (2019). R: A Language and Environment for Statistical Computing. R Foundation for Statistical Computing. https://www.R-project.org/

Rodgers, R. F., \& Paxton, S. J. (2014). The impact of indicated prevention and early intervention on co-morbid eating disorder and depressive symptoms: a systematic review. Journal of Eating Disorders, 2(1), 30.

Salk, R. H., Hyde, J. S., \& Abramson, L. Y. (2017). Gender differences in depression in representative national samples: Meta-analyses of diagnoses and symptoms. Psychological Bulletin, 143(8), 783-822.

Sharpe, H., Patalay, P., Choo, T.-H., Wall, M., Mason, S. M., Goldschmidt, A. B., \& NeumarkSztainer, D. (2018). Bidirectional associations between body dissatisfaction and depressive symptoms from adolescence through early adulthood. Development and Psychopathology, 30(4), 1447-1458.

Social Media Fact Sheet. (2021, April 7). Pew Research Center. https://www.pewresearch.org/internet/fact-sheet/social-media/ 
Stice, E. (1994). Review of the evidence for a sociocultural model of bulimia nervosa and an exploration of the mechanisms of action. Clinical Psychology Review, 14(7), 633-661.

Stice, E., \& Bearman, S. K. (2001). Body-Image and Eating Disturbances Prospectively Predict Increases in Depressive Symptoms in Adolescent Girls: A Growth Curve Analysis. Developmental Psychology, 37(5), 597-607.

Stice, E., Hayward, C., Cameron, R. P., Killen, J. D., \& Barr Taylor, C. (2000). Body-Image and Eating Disturbances Predict Onset of Depression Among Female Adolescents: A Longitudinal Study. Journal of Abnormal Psychology, 109(3), 438-444.

Stice, E., Marti, C. N., Shaw, H., \& Rohde, P. (2019). Meta-analytic review of dissonance-based eating disorder prevention programs: Intervention, participant, and facilitator features that predict larger effects. Clinical Psychology Review, 70, 91-107.

Stice, E., Rohde, P., Gau, J., \& Shaw, H. (2009). An effectiveness trial of a dissonance-based eating disorder prevention program for high-risk adolescent girls. Journal of Consulting and Clinical Psychology, 77(5), 825-834.

Stice, E., \& Shaw, H. (2004). Eating disorder prevention programs: a meta-analytic review. Psychological Bulletin, 130(2), 206-227.

Stice, E., Shaw, H., Bohon, C., Marti, C. N., \& Rohde, P. (2009). A meta-analytic review of depression prevention programs for children and adolescents: Factors that predict magnitude of intervention effects. Journal of Consulting and Clinical Psychology, 77(3), 486-503.

Stice, E., Shaw, H., Burton, E., \& Wade, E. (2006). Dissonance and healthy weight eating disorder prevention programs: A randomized efficacy trial. Journal of Consulting and Clinical Psychology, 74(2), 263-275.

Stice, E., \& Shaw, H. E. (2002). Role of body dissatisfaction in the onset and maintenance of eating pathology: a synthesis of research findings. Journal of Psychosomatic Research, 
BD Intervention Effects on Depression

53(5), 985-993.

Stice, E., \& Van Ryzin, M. J. (2019). A prospective test of the temporal sequencing of risk factor emergence in the dual pathway model of eating disorders. Journal of Abnormal Psychology, 128(2), 119-128.

Stockings, E. A., Degenhardt, L., Dobbins, T., Lee, Y. Y., Erskine, H. E., Whiteford, H. A., \& Patton, G. (2016). Preventing depression and anxiety in young people: a review of the joint efficacy of universal, selective and indicated prevention. Psychological Medicine, 46(1), 1126.

Trost, A. S. (2006). The Healthy Image Partnership (HIP) Parents Program: The Role of Parental Involvement in Eating Disorder Prevention. https://repositories.lib.utexas.edu/bitstream/handle/2152/2976/trostd28599.pdf?sequence= 2

Viechtbauer, W. (2010). Conducting Meta-Analyses in R with the metafor Package. Journal of Statistical Software, Articles, 36(3), 1-48.

Wang, S. B., Haynos, A. F., Wall, M. M., Chen, C., Eisenberg, M. E., \& Neumark-Sztainer, D. (2019). Fifteen-Year Prevalence, Trajectories, and Predictors of Body Dissatisfaction From Adolescence to Middle Adulthood. Clinical Psychological Science, 7(6), 1403-1415.

Watson, D., \& Clark, L. A. (1994). The PANAS-X: Manual for the Positive and Negative Affect Schedule - Expanded Form. In University of lowa. https://doi.org/10.17077/48vt-m4t2 Weisz, J. R., Kuppens, S., Ng, M. Y., Eckshtain, D., Ugueto, A. M., Vaughn-Coaxum, R., Jensen-Doss, A., Hawley, K. M., Krumholz Marchette, L. S., Chu, B. C., Weersing, V. R., \& Fordwood, S. R. (2017). What five decades of research tells us about the effects of youth psychological therapy: A multilevel meta-analysis and implications for science and practice. The American Psychologist, 72(2), 79-117.

Werner-Seidler, A., Perry, Y., Calear, A. L., Newby, J. M., \& Christensen, H. (2017). School- 
BD Intervention Effects on Depression

based depression and anxiety prevention programs for young people: A systematic review and meta-analysis. In Clinical Psychology Review (Vol. 51, pp. 30-47).

https://doi.org/10.1016/j.cpr.2016.10.005

Wilksch, S. M., Paxton, S. J., Byrne, S. M., Austin, S. B., McLean, S. A., Thompson, K. M., Dorairaj, K., \& Wade, T. D. (2015). Prevention Across the Spectrum: a randomized controlled trial of three programs to reduce risk factors for both eating disorders and obesity. In Psychological Medicine (Vol. 45, Issue 9, pp. 1811-1823).

https://doi.org/10.1017/s003329171400289x

Wilksch, S. M., Tiggemann, M., \& Wade, T. D. (2006). Impact of interactive school-based media literacy lessons for reducing internalization of media ideals in young adolescent girls and boys. The International Journal of Eating Disorders, 39(5), 385-393.

Wilksch, S. M., \& Wade, T. D. (2009). Reduction of shape and weight concern in young adolescents: a 30-month controlled evaluation of a media literacy program. Journal of the American Academy of Child and Adolescent Psychiatry, 48(6), 652-661.

Zimmerman, M., Ellison, W., Young, D., Chelminski, I., \& Dalrymple, K. (2015). How many different ways do patients meet the diagnostic criteria for major depressive disorder? Comprehensive Psychiatry, 56, 29-34. 
BD Intervention Effects on Depression

Table 1. Included Study Characteristics.

\begin{tabular}{|c|c|c|c|c|c|c|c|c|c|c|c|c|c|}
\hline Article & Country & $\begin{array}{c}\text { M } \\
\text { Age }\end{array}$ & $\begin{array}{c}\% \\
\text { Femal } \\
\text { e }\end{array}$ & $\begin{array}{c}\% \\
\text { Non- } \\
\text { White }\end{array}$ & Intervention(s) & $\begin{array}{c}\text { Interventio } \\
\text { n Type }\end{array}$ & $\begin{array}{c}\mathrm{N} \\
\text { (analyzed } \\
\text { ): } \\
\text { Treatmen } \\
\mathbf{t}\end{array}$ & $\begin{array}{c}\mathbf{N} \\
\text { (analyzed } \\
\text { ): Control }\end{array}$ & Intervention Target & $\begin{array}{l}\text { Interventi } \\
\text { on } \\
\text { Delivery } \\
\text { Format }\end{array}$ & $\begin{array}{c}\text { Interven } \\
\text { tion } \\
\text { Length } \\
\text { (minutes } \\
\text { ) }\end{array}$ & $\begin{array}{l}\text { Control } \\
\text { Conditi } \\
\text { on }\end{array}$ & $\begin{array}{c}\text { Outcome } \\
\text { Type }\end{array}$ \\
\hline $\begin{array}{l}\text { Amaral } \\
\text { et al., } \\
2019\end{array}$ & Brazil & 16.25 & 100 & NR & The Body Project & $\begin{array}{r}\text { Indicated } \\
\text { Prevention }\end{array}$ & 79 & 62 & $\begin{array}{r}\text { Thin-ideal } \\
\text { internalization }\end{array}$ & $\begin{array}{r}\text { Group } \\
\text { Therapy }\end{array}$ & 240 & $\begin{array}{r}\text { Waitlist/ } \\
\text { no- } \\
\text { treatmen } \\
\mathrm{t}\end{array}$ & $\begin{array}{r}\text { Depression } \\
\text { Symptoms } \\
\text { and Trait } \\
\text { Negative } \\
\text { Affect }\end{array}$ \\
\hline $\begin{array}{l}\text { Atkinso } \\
\text { n \& } \\
\text { Wade, } \\
2015\end{array}$ & Australia & 15.74 & 100 & 16 & $\begin{array}{r}\text { Dissonance-based } \\
\text { intervention; } \\
\text { mindfulness-based } \\
\text { intervention }\end{array}$ & $\begin{array}{r}\text { Selective } \\
\text { Prevention }\end{array}$ & $104 ; 129$ & 97 & $\begin{array}{r}\text { Thin-ideal } \\
\text { internalization; } \\
\text { mindfulness and self- } \\
\text { compassion }\end{array}$ & $\begin{array}{r}\text { Group } \\
\text { Therapy }\end{array}$ & NR & $\begin{array}{r}\text { Waitlist/ } \\
\text { no- } \\
\text { treatmen } \\
\mathrm{t}\end{array}$ & $\begin{array}{r}\text { Trait } \\
\text { Negative } \\
\text { Affect }\end{array}$ \\
\hline $\begin{array}{l}\text { Diedric } \\
\text { hs et } \\
\text { al., } \\
2015\end{array}$ & England & 12.17 & 50.38 & 21.91 & $\begin{array}{r}\text { Dove Confident Me: } \\
\text { Single Session }\end{array}$ & $\begin{array}{r}\text { Universal } \\
\text { Prevention }\end{array}$ & $\begin{array}{r}729 \\
\text { (teacher- } \\
\text { led } \\
\text { condition); } \\
551 \\
\text { (researche } \\
\text { r-led } \\
\text { condition) }\end{array}$ & 427 & $\begin{array}{r}\text { Appearance ideals, } \\
\text { media } \\
\text { internalization/literac } \\
\mathrm{y}, \text { and appearance } \\
\text { comparisons }\end{array}$ & $\begin{array}{r}\text { Group } \\
\text { Therapy }\end{array}$ & 90 & $\begin{array}{r}\text { Waitlist/ } \\
\text { no- } \\
\text { treatmen } \\
\mathrm{t}\end{array}$ & $\begin{array}{r}\text { Trait } \\
\text { Negative } \\
\text { Affect }\end{array}$ \\
\hline $\begin{array}{l}\text { Diedric } \\
\text { hs et } \\
\text { al., } \\
2016\end{array}$ & England & 13 & 100 & 10.21 & $\begin{array}{r}\text { Dove Self-Esteem } \\
\text { Project Website for } \\
\text { Parents }\end{array}$ & $\begin{array}{r}\text { Indicated } \\
\text { Prevention }\end{array}$ & $\begin{array}{r}81 \\
\text { (website } \\
\text { unstructur } \\
\text { ed } \\
\text { condition); } \\
74 \\
\text { (website } \\
\text { tailored } \\
\text { condition) }\end{array}$ & 80 & $\begin{array}{r}\text { Appearance ideals, } \\
\text { appearance } \\
\text { conversations and } \\
\text { teasing, interpersonal } \\
\text { relationships, and } \\
\text { body acceptance }\end{array}$ & $\begin{array}{r}\text { Self- } \\
\text { administere } \\
\mathrm{d}\end{array}$ & $\sim 30$ & $\begin{array}{r}\text { Waitlist/ } \\
\text { no- } \\
\text { treatmen } \\
\mathrm{t}\end{array}$ & $\begin{array}{r}\text { Trait } \\
\text { Negative } \\
\text { Affect }\end{array}$ \\
\hline
\end{tabular}


BD Intervention Effects on Depression

\begin{tabular}{|c|c|c|c|c|c|c|c|c|c|c|c|c|c|}
\hline $\begin{array}{l}\text { Eickma } \\
\text { n et al., } \\
2018\end{array}$ & $\begin{array}{r}\text { United } \\
\text { States }\end{array}$ & $\begin{array}{r}\mathrm{NR} \\
\text { (majo } \\
\text { rity } \\
\mathrm{HS} \\
\text { fresh } \\
\text { men) }\end{array}$ & 86.09 & 16.5 & $\begin{array}{r}\text { REbeL Peer } \\
\text { Education Program }\end{array}$ & $\begin{array}{r}\text { Universal } \\
\text { Prevention }\end{array}$ & 48 & 23 & $\begin{array}{r}\text { Body image, eating } \\
\text { disorder signs and } \\
\text { symptoms, mindful } \\
\text { eating and exercise, } \\
\text { self-esteem, weight } \\
\text { bias, bullying, and } \\
\text { media literacy }\end{array}$ & $\begin{array}{r}\text { Group } \\
\text { Therapy }\end{array}$ & $\begin{array}{r}\sim 1530 \\
\text { (weekly } \\
30- \\
60 \mathrm{minr} \\
\text { meetings } \\
\text { for } 8 \\
\text { months) }\end{array}$ & $\begin{array}{r}\text { Waitlist/ } \\
\text { no- } \\
\text { treatmen } \\
\mathrm{t}\end{array}$ & $\begin{array}{r}\text { Trait } \\
\text { Negative } \\
\text { Affect }\end{array}$ \\
\hline $\begin{array}{l}\text { Gumz } \\
\text { et al., } \\
2017\end{array}$ & Germany & 14.6 & 55.65 & NR & $\begin{array}{r}\text { Gender-adapted } \\
\text { prevention program }\end{array}$ & $\begin{array}{r}\text { Universal } \\
\text { Prevention }\end{array}$ & 1020 & 981 & $\begin{array}{r}\text { Western beauty } \\
\text { ideals, media literacy, } \\
\text { eating disorder risk } \\
\text { factors, and nutrition }\end{array}$ & $\begin{array}{l}\text { Group } \\
\text { Therapy }\end{array}$ & 270 & $\begin{array}{r}\text { Waitlist/ } \\
\text { no- } \\
\text { treatmen } \\
\mathrm{t}\end{array}$ & $\begin{array}{r}\text { Depression } \\
\text { Symptoms }\end{array}$ \\
\hline $\begin{array}{l}\text { Heinick } \\
\text { e et al., } \\
2007\end{array}$ & Australia & 14.4 & 100 & 4.82 & $\begin{array}{r}\text { My Body, My Life: } \\
\text { Body Image Program } \\
\text { for Adolescent } \\
\text { Girls }\end{array}$ & $\begin{array}{r}\text { Indicated } \\
\text { Prevention }\end{array}$ & 36 & 37 & $\begin{array}{r}\text { Body image, } \\
\text { unhealthy eating } \\
\text { patterns, appearance } \\
\text { related pressures, } \\
\text { teasing, and } \\
\text { comparisons }\end{array}$ & $\begin{array}{r}\text { Digital/onli } \\
\text { ne Group } \\
\text { Therapy }\end{array}$ & 540 & $\begin{array}{r}\text { Waitlist/ } \\
\text { no- } \\
\text { treatmen } \\
\mathrm{t}\end{array}$ & $\begin{array}{r}\text { Depression } \\
\text { Symptoms }\end{array}$ \\
\hline $\begin{array}{l}\text { Linville } \\
\text { et al., } \\
2015\end{array}$ & $\begin{array}{r}\text { United } \\
\text { States }\end{array}$ & 14.9 & 100 & 28 & The Body Project & $\begin{array}{r}\text { Indicated } \\
\text { Prevention }\end{array}$ & 43 & 23 & $\begin{array}{r}\text { Thin-ideal } \\
\text { internalization }\end{array}$ & $\begin{array}{r}\text { Group } \\
\text { Therapy }\end{array}$ & 240 & $\begin{array}{l}\text { Psychoe } \\
\text { ducation }\end{array}$ & $\begin{array}{r}\text { Trait } \\
\text { Negative } \\
\text { Affect }\end{array}$ \\
\hline $\begin{array}{l}\text { Stice et } \\
\text { al., } \\
2006\end{array}$ & $\begin{array}{r}\text { United } \\
\text { States }\end{array}$ & 17 & 100 & 42 & $\begin{array}{r}\text { The Body Project; } \\
\text { Healthy Weight } \\
\text { Intervention }\end{array}$ & $\begin{array}{r}\text { Indicated } \\
\text { Prevention }\end{array}$ & $115 ; 117$ & $126 ; 123$ & $\begin{array}{r}\text { Thin-ideal } \\
\text { internalization; } \\
\text { healthy weight } \\
\text { management } \\
\text { skills/behaviors }\end{array}$ & $\begin{array}{l}\text { Group } \\
\text { Therapy }\end{array}$ & 180 & $\begin{array}{r}\text { Waitlist/ } \\
\text { no- } \\
\text { treatmen } \\
\mathrm{t} \text {; } \\
\text { expressi } \\
\mathrm{ve} \\
\text { writing } \\
\text { conditio } \\
\mathrm{n}\end{array}$ & $\begin{array}{r}\text { Trait } \\
\text { Negative } \\
\text { Affect }\end{array}$ \\
\hline $\begin{array}{l}\text { Stice et } \\
\text { al., } \\
2009\end{array}$ & $\begin{array}{r}\text { United } \\
\text { States }\end{array}$ & 15.7 & 100 & 19 & The Body Project & $\begin{array}{r}\text { Indicated } \\
\text { Prevention }\end{array}$ & 139 & 167 & $\begin{array}{r}\text { Thin-ideal } \\
\text { internalization }\end{array}$ & $\begin{array}{l}\text { Group } \\
\text { Therapy }\end{array}$ & 240 & $\begin{array}{l}\text { Psychoe } \\
\text { ducation }\end{array}$ & $\begin{array}{r}\text { Depression } \\
\text { Symptoms }\end{array}$ \\
\hline
\end{tabular}


BD Intervention Effects on Depression

\begin{tabular}{|c|c|c|c|c|c|c|c|c|c|c|c|c|c|}
\hline $\begin{array}{l}\text { Trost, } \\
2006\end{array}$ & $\begin{array}{r}\text { United } \\
\text { States }\end{array}$ & 12.43 & 100 & 19.48 & $\begin{array}{r}\text { The Healthy Image } \\
\text { Partnership (HIP) } \\
\text { Parents Program }\end{array}$ & $\begin{array}{r}\text { Indicated } \\
\text { Prevention }\end{array}$ & $\begin{array}{r}39 \\
\text { (parent- } \\
\text { daughter } \\
\text { dyads) }\end{array}$ & $\begin{array}{r}42 \\
\text { (parent- } \\
\text { daughter } \\
\text { dyads) }\end{array}$ & $\begin{array}{r}\text { Thin-ideal } \\
\text { internalization and } \\
\text { communication of the } \\
\text { thin-ideal to } \\
\text { daughters }\end{array}$ & $\begin{array}{r}\text { Group } \\
\text { Therapy }\end{array}$ & 270 & $\begin{array}{r}\text { Waitlist/ } \\
\text { no- } \\
\text { treatmen } \\
\mathrm{t}\end{array}$ & $\begin{array}{r}\text { Trait } \\
\text { Negative } \\
\text { Affect }\end{array}$ \\
\hline $\begin{array}{l}\text { Wilksc } \\
\text { h \& } \\
\text { Wade, } \\
2009\end{array}$ & Australia & 13.62 & 50.56 & $\begin{array}{r}\text { "Scho } \\
\text { ols } \\
\text { comp } \\
\text { osed } \\
\text { typica } \\
\text { lly of } \\
\text { white } \\
\text { studen } \\
\text { ts } \\
\text { from } \\
\text { middl } \\
\text { e- } \\
\text { incom } \\
\mathrm{e} \\
\text { famili } \\
\text { es." }\end{array}$ & Media Smart & $\begin{array}{r}\text { Universal } \\
\text { Prevention }\end{array}$ & 220 & 253 & $\begin{array}{r}\text { Media- } \\
\text { internalization/literac } \\
\mathrm{y}\end{array}$ & $\begin{array}{r}\text { Group } \\
\text { Therapy }\end{array}$ & 400 & $\begin{array}{r}\text { Waitlist/ } \\
\text { no- } \\
\text { treatmen } \\
\mathrm{t}\end{array}$ & $\begin{array}{c}\text { Depression } \\
\text { Symptoms }\end{array}$ \\
\hline $\begin{array}{l}\text { Wilksc } \\
\text { h et al., } \\
2015\end{array}$ & Australia & 13.21 & 63.83 & $\begin{array}{r}\text { “...pre } \\
\text { domin } \\
\text { antly } \\
\text { Cauca } \\
\text { sian } \\
\text { sampl } \\
\text { e as } \\
\text { reflect } \\
\text { ing } \\
\text { Austra } \\
\text { lian } \\
\text { societ } \\
\text { y.” }\end{array}$ & $\begin{array}{r}\text { Media Smart; The } \\
\text { Helping, } \\
\text { Encouraging, } \\
\text { Listening and } \\
\text { Protecting Peers } \\
\text { (HELPP) initiative }\end{array}$ & $\begin{array}{r}\text { Universal } \\
\text { Prevention }\end{array}$ & $247 ; 199$ & 410 & $\begin{array}{r}\text { Media } \\
\text { internalization/literac } \\
\mathrm{y} ; \text { media } \\
\text { internalization, } \\
\text { appearance ideals and } \\
\text { comparisons, and } \\
\text { dieting }\end{array}$ & $\begin{array}{r}\text { Group } \\
\text { Therapy }\end{array}$ & 400 & $\begin{array}{r}\text { Waitlist/ } \\
\text { no- } \\
\text { treatmen } \\
\mathrm{t}\end{array}$ & $\begin{array}{r}\text { Depression } \\
\text { Symptoms }\end{array}$ \\
\hline
\end{tabular}


BD Intervention Effects on Depression

Table 2. Moderator and Subgroup Analyses (Post-intervention)

\begin{tabular}{|c|c|c|c|c|c|c|}
\hline \multirow[b]{3}{*}{ moderator } & \multirow[b]{3}{*}{ level } & \multicolumn{3}{|c|}{ Subgroup Analys } & \multicolumn{2}{|c|}{ Moderator Test } \\
\hline & & nStudi & & abgroup s & ubgrou & overall \\
\hline & & es & $\mathbf{S}$ & Est & pP coefoverallStat & $\mathbf{P}$ \\
\hline Year & & 13 & 21 & & $0.008_{0.573}^{\mathrm{t}(6.588)=}=$ & 0.586 \\
\hline \multirow[t]{3}{*}{ Country } & & & & & $\begin{array}{l}\mathrm{t}(4.896)=- \\
1.545\end{array}$ & 0.184 \\
\hline & $\begin{array}{l}\text { Other (Non-North } \\
\text { America) }\end{array}$ & 8 & 13 & -0.117 & 0.041 & \\
\hline & $\overline{U S A}$ & 5 & 8 & -0.364 & 0.067 & \\
\hline \multirow[t]{3}{*}{ Intervention Type } & & & & & $\begin{array}{l}t(8.183)= \\
1.149\end{array}$ & 0.283 \\
\hline & Indicated prevention & 7 & 12 & -0.269 & 0.023 & \\
\hline & Universal prevention & 5 & 7 & -0.153 & 0.112 & \\
\hline \multirow[t]{3}{*}{ Risk Screening } & & & & & $\begin{array}{l}t(7.331)=- \\
1.085\end{array}$ & 0.312 \\
\hline & No risk screening & 6 & 9 & -0.135 & 0.076 & \\
\hline & Screen on BD & 6 & 11 & -0.242 & 0.046 & \\
\hline Mean Age & & 12 & 20 & & $\begin{array}{c}-t(4.094)=- \\
0.0421 .625\end{array}$ & 0.178 \\
\hline Percent Female & & 13 & 21 & & $\begin{array}{c}-\mathrm{t}(7.157)=- \\
0.0031 .648\end{array}$ & 0.142 \\
\hline Percent Non-White & & 11 & 18 & & $\begin{array}{c}-\mathrm{t}(2.173)=- \\
0.0051 .251\end{array}$ & 0.329 \\
\hline Length (Minutes) & & 12 & 19 & & $\begin{array}{c}-t(1.692)=- \\
0.0013 .008\end{array}$ & 0.116 \\
\hline Length (Sessions) & & 13 & 21 & & $\begin{array}{c}-t(1.55)=- \\
0.0253 .055\end{array}$ & 0.125 \\
\hline Length (Days) & & 13 & 21 & & $\begin{array}{c}-t(1.221)=- \\
0.0047 .225\end{array}$ & 0.060 \\
\hline $\begin{array}{l}\text { Treatment } \\
\text { Completion Rate }\end{array}$ & & 8 & 14 & & $0.007_{1.513}^{\mathrm{t}(2.918)=}$ & 0.230 \\
\hline Outcome & & & & & $\begin{array}{l}\mathrm{t}(8.687)=- \\
0.79\end{array}$ & 0.450 \\
\hline
\end{tabular}

Depression

$\begin{array}{llll}6 & 7 & -0.166 & 0.075\end{array}$


BD Intervention Effects on Depression

\begin{tabular}{|c|c|c|c|c|c|c|}
\hline & \multicolumn{6}{|l|}{ Symptomatology } \\
\hline & Trait Negative Affect & 814 & -0.261 & 0.030 & & \\
\hline \multirow[t]{3}{*}{$\begin{array}{l}\text { Facilitator } \\
\text { Supervision }\end{array}$} & & & & & $\begin{array}{l}\mathrm{t}(7.974)=- \\
0.205\end{array}$ & 0.843 \\
\hline & No supervision & 69 & -0.179 & 0.043 & & \\
\hline & Supervision & 610 & -0.239 & 0.083 & & \\
\hline $\begin{array}{l}\text { Post-test Data } \\
\text { Availability }\end{array}$ & & 1321 & & & $0.006_{1.175}^{\mathrm{t}(2.003)=}$ & 0.361 \\
\hline \multirow[t]{3}{*}{ Randomized Units } & & & & & $\begin{array}{l}t(5.573)=- \\
1.734\end{array}$ & 0.137 \\
\hline & $\overline{<30 \text { per group }}$ & 711 & -0.123 & 0.055 & & \\
\hline & $>=30$ per group & 5 & -0.307 & 0.043 & & \\
\hline
\end{tabular}


BD Intervention Effects on Depression

Table 3. Moderator and Subgroup Analyses (Follow-Up)

\begin{tabular}{|c|c|c|c|c|c|c|}
\hline \multirow[b]{2}{*}{ moderator } & \multirow[b]{2}{*}{ level } & \multicolumn{3}{|c|}{ Subgroup Analysi } & \multicolumn{2}{|c|}{ Moderator Test } \\
\hline & & es & s & Est & pP coefoverallStat & P \\
\hline Year & & 10 & 29 & & $0.003_{0.423}^{t(3.886)=}$ & 0.695 \\
\hline \multirow[t]{3}{*}{ Country } & & & & & $\begin{array}{l}\mathrm{t}(2.951)= \\
0.137\end{array}$ & 0.900 \\
\hline & $\begin{array}{l}\text { Other (Non-North } \\
\text { America) }\end{array}$ & 6 & 17 & -0.050 & 0.168 & \\
\hline & $\overline{U S A}$ & 4 & 12 & -0.037 & 0.688 & \\
\hline \multirow[t]{3}{*}{ Intervention Type } & & & & & $\begin{array}{l}t(4.717)= \\
0.373\end{array}$ & 0.726 \\
\hline & Indicated prevention & 5 & 16 & -0.073 & 0.398 & \\
\hline & Universal prevention & 4 & 9 & -0.042 & 0.268 & \\
\hline \multirow[t]{3}{*}{ Risk Screening } & & & & & $\begin{array}{l}t(4.45)=- \\
0.402\end{array}$ & 0.706 \\
\hline & No risk screening & 5 & 13 & -0.038 & 0.235 & \\
\hline & Screen on BD & 5 & 16 & -0.073 & 0.398 & \\
\hline Mean Age & & 10 & 29 & & $\begin{array}{c}-\mathrm{t}(3.37)=- \\
0.0060 .283\end{array}$ & 0.793 \\
\hline Percent Female & & 10 & 29 & & $\begin{array}{c}-\mathrm{t}(5.977)=- \\
0.0010 .375\end{array}$ & 0.721 \\
\hline Percent Non-White & & 9 & 28 & & $\begin{array}{c}0.001+1.956)= \\
0.116\end{array}$ & 0.918 \\
\hline Length (Minutes) & & 9 & 25 & & $0.000_{0.515}^{t(2.908)=-}$ & 0.643 \\
\hline Length (Sessions) & & 10 & 29 & & $\begin{array}{c}-\mathrm{t}(2.179)=- \\
0.0131 .817\end{array}$ & 0.200 \\
\hline Length (Days) & & 10 & 29 & & $\begin{array}{c}-t(3.055)=- \\
0.0020 .845\end{array}$ & 0.459 \\
\hline $\begin{array}{l}\text { Treatment } \\
\text { Completion Rate }\end{array}$ & & 5 & 19 & & $\begin{array}{c}-\mathrm{t}(2.552)=- \\
0.0051 .783\end{array}$ & 0.188 \\
\hline
\end{tabular}


BD Intervention Effects on Depression

Outcome

$\mathrm{t}(5.184)=-$

0.159

0.879

\begin{tabular}{|c|c|c|c|c|c|c|c|}
\hline & $\begin{array}{l}\text { Depression } \\
\text { Symptomatology }\end{array}$ & 4 & 9 & -0.042 & 0.307 & & \\
\hline & Trait Negative Affect & 6 & 20 & -0.060 & 0.324 & & \\
\hline \multirow[t]{3}{*}{ Follow-up Length } & & & & & & $\begin{array}{l}t(3.115)=- \\
0.363\end{array}$ & 0.740 \\
\hline & $\begin{array}{l}\text { Between } 3 \text { and } 12 \\
\text { weeks }\end{array}$ & 5 & 8 & -0.079 & 0.387 & & \\
\hline & $\begin{array}{l}\text { Greater than } 12 \\
\text { weeks }\end{array}$ & 7 & 21 & -0.047 & 0.191 & & \\
\hline \multirow[t]{3}{*}{$\begin{array}{l}\text { Facilitator } \\
\text { Supervision }\end{array}$} & & & & & & $\begin{array}{l}t(3.519)= \\
1.773\end{array}$ & 0.161 \\
\hline & No supervision & 4 & 11 & -0.081 & 0.125 & & \\
\hline & Supervision & 5 & 14 & -0.016 & 0.498 & & \\
\hline $\begin{array}{l}\text { Follow-up Data } \\
\text { Availability }\end{array}$ & & 10 & 29 & & & 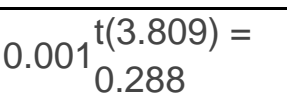 & 0.788 \\
\hline \multirow[t]{3}{*}{ Randomized Units } & & & & & & $\begin{array}{l}\mathrm{t}(2.244)= \\
0.469\end{array}$ & 0.680 \\
\hline & $<30$ per group & 6 & 17 & -0.050 & 0.168 & & \\
\hline & $>=30$ per group & 3 & 11 & -0.009 & 0.919 & & \\
\hline
\end{tabular}




\section{BD Intervention Effects on Depression}

Figure 1. CONSORT Flowchart

Citations identified in systemic search $(n=1,458)$

Excluded $(n=1,410)$

Reasons:

- Duplicated $(n=258)$

- Did not meet criteria $(1,152)$

Full-text studies retrieved $(n=48)$

Excluded $(n=35)$

Reasons (not mutually exclusive):

- Duplicated $(n=5)$

- Same data as previous study $(n=2)$

- Outcome data not available $(n=3)$

- Intervention target not eligible $(n=6)$

- Age not in range $(n=6)$

- Not RCT $(n=5)$

- No non-intervention control $(n=11)$

- No eligible outcome $(n=14)$

Studies meeting inclusion criteria $(n=13)$ 


\section{BD Intervention Effects on Depression}

\section{Figure 2. Forest Plot (Post-intervention)}

Amaral et al 2019

Atkinson \& Wade 2015

Diedrichs et al 2015

Diedrichs et al 2016

Eickman et al 2018

Gumz et al 2017

Heinicke et al 2007

Linville et al 2015

Stice et al 2006

Stice et al 2009

Trost 2006

Wilksch \& Wade 2009

Wilksch et al 2015

reatment (1) vs Control, Depression Symptomatology Treatment (2) vs Control, Depression Symptomatology

Treatment vs Control, Depression Symptomatology Treatment vs Control, Trait Negative Affect

Treatment (1) vs Control, Trait Negative Affect Treatment (2) vs Control, Trait Negative Affect

Treatment (1) vs Control, Trait Negative Affect Treatment (2) vs Control, Trait Negative Affect

Treatment (1) vs Control, Trait Negative Affect Treatment (2) vs Control, Trait Negative Affect

Treatment vs Control, Trait Negative Affect

Treatment vs Control, Depression Symptomatology

Treatment vs Control, Depression Symptomatology

Treatment vs Control, Trait Negative Affect

Treatment (1) vs Control (1), Trait Negative Affect Treatment (1) vs Control (2), Trait Negative Affect Treatment (2) vs Control (1), Trait Negative Affect Treatment (2) vs Control (2), Trait Negative Affect

Treatment vs Control, Depression Symptomatology

Treatment vs Control, Trait Negative Affect Treatment vs Control, Depression Symptomatology

\section{Overall Estimate}

Overall Estimate
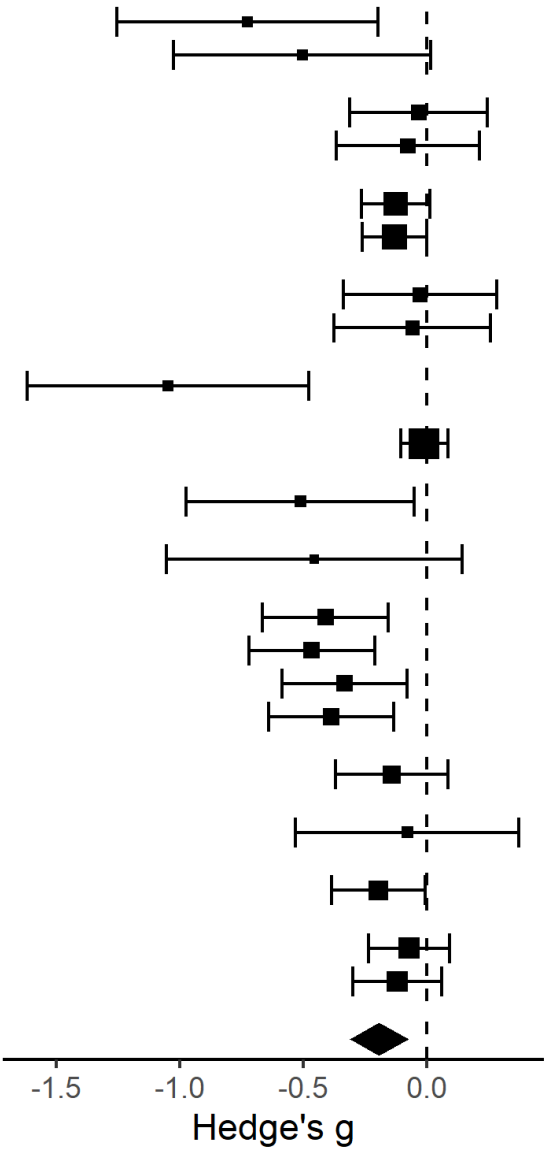


\section{BD Intervention Effects on Depression}

Figure 3. Forest Plot (Follow-up)

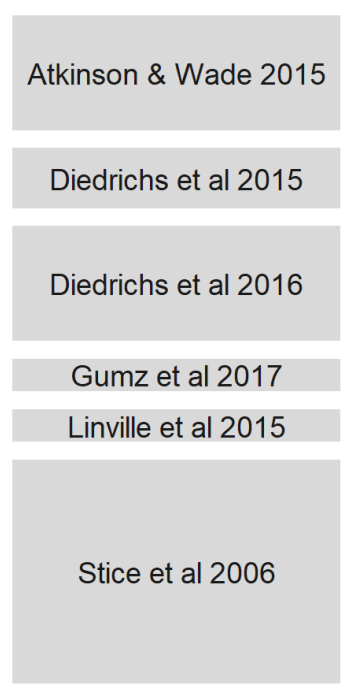

Stice et al 2009

Trost 2006

Wilksch \& Wade 2009

Wilksch et al 2015
Treatment (1) vs Control, Trait Negative Affect (26 weeks) Treatment (1) vs Control, Trait Negative Affect (4 weeks Treatment (2) vs Control, Trait Negative Affect (26 weeks) Treatment (2) vs Control, Trait Negative Affect (4 weeks)

Treatment (1) vs Control, Trait Negative Affect (7 weeks) Treatment (2) vs Control, Trait Negative Affect (7 weeks)

Treatment (1) vs Control, Trait Negative Affect (52 weeks) Treatment (1) vs Control, Trait Negative Affect (6 weeks) Treatment (2) vs Control, Trait Negative Affect (52 weeks) Treatment (2) vs Control, Trait Negative Affect (6 weeks)

Treatment vs Control, Depression Symptomatology (26 weeks)

Treatment vs Control, Trait Negative Affect (12 weeks)

Treatment (1) vs Control (1), Trait Negative Affect (24 weeks) Treatment (1) vs Control (1), Trait Negative Affect (52 weeks) Treatment (1) vs Control (2), Trait Negative Affect 24 weeks Treatment (1) vs Control (2), Trait Negative Affect (52 weeks) Treatment (2) vs Control (1), Trait Negative Affect (24 weeks) Treatment (2) vs Control (1), Trait Negative Affect (52 weeks Treatment (2) vs Control (2), Trait Negative Affect (24 weeks) Treatment (2) vs Control (2), Trait Negative Affect (52 weeks)

Treatment vs Control, Depression Symptomatology (26 weeks) Treatment vs Control, Depression Symptomatology (52 weeks)

Treatment vs Control, Trait Negative Affect (12 weeks)

Treatment vs Control, Depression Symptomatology (130 weeks) Treatment vs Control, Depression Symptomatology (26 weeks)

Treatment (1) vs Control, Depression Symptomatology (26 weeks) Treatment (1) vs Control, Depression Symptomatology (52 weeks) Treatment (2) vs Control, Depression Symptomatology (26 weeks) Treatment (2) vs Control, Depression Symptomatology (52 weeks)
Overall Estimate
Overall Estimate

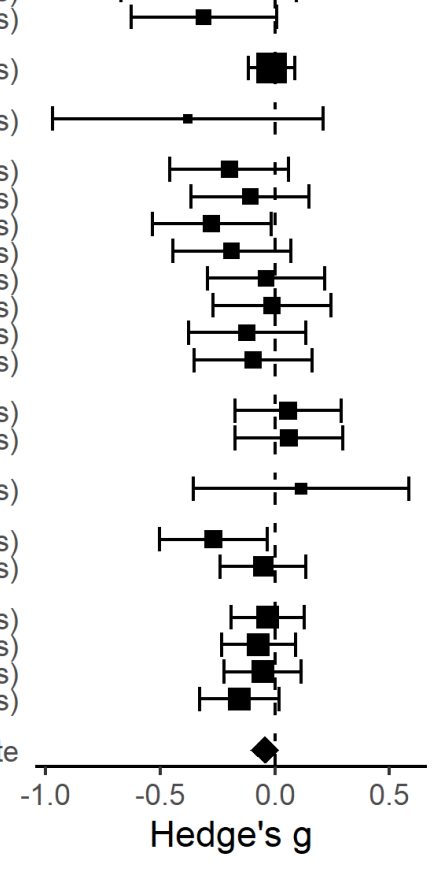


BD Intervention Effects on Depression

Figure 4. Funnel Plot (Post-intervention)

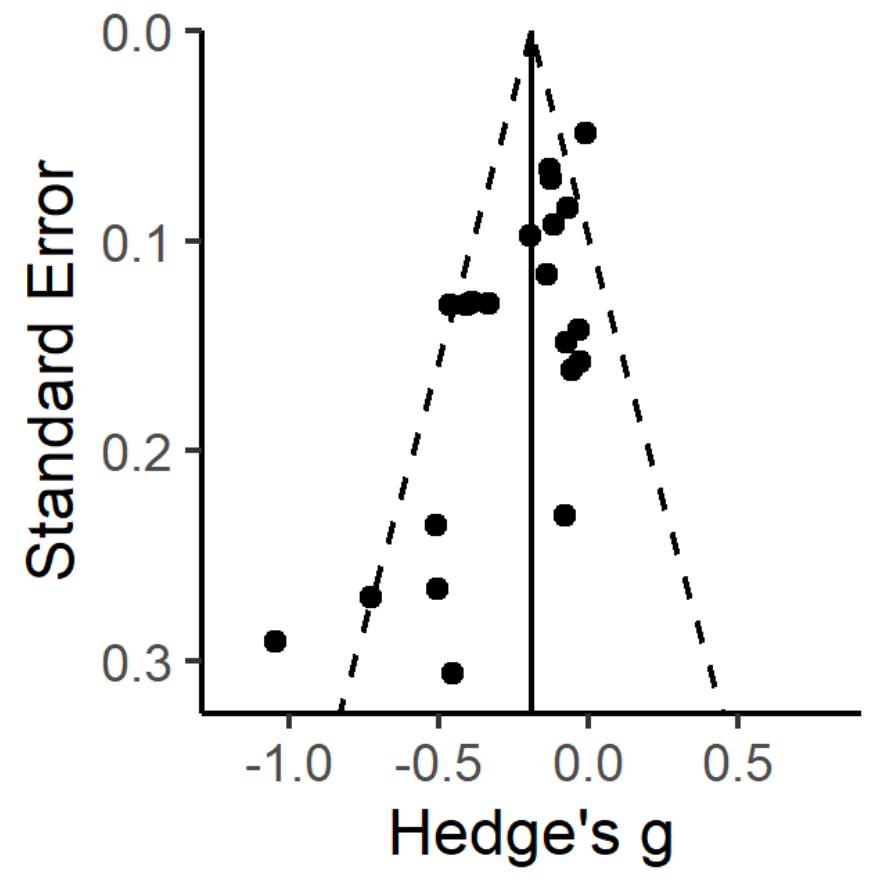


BD Intervention Effects on Depression

Figure 5. Funnel Plot (Follow-up)

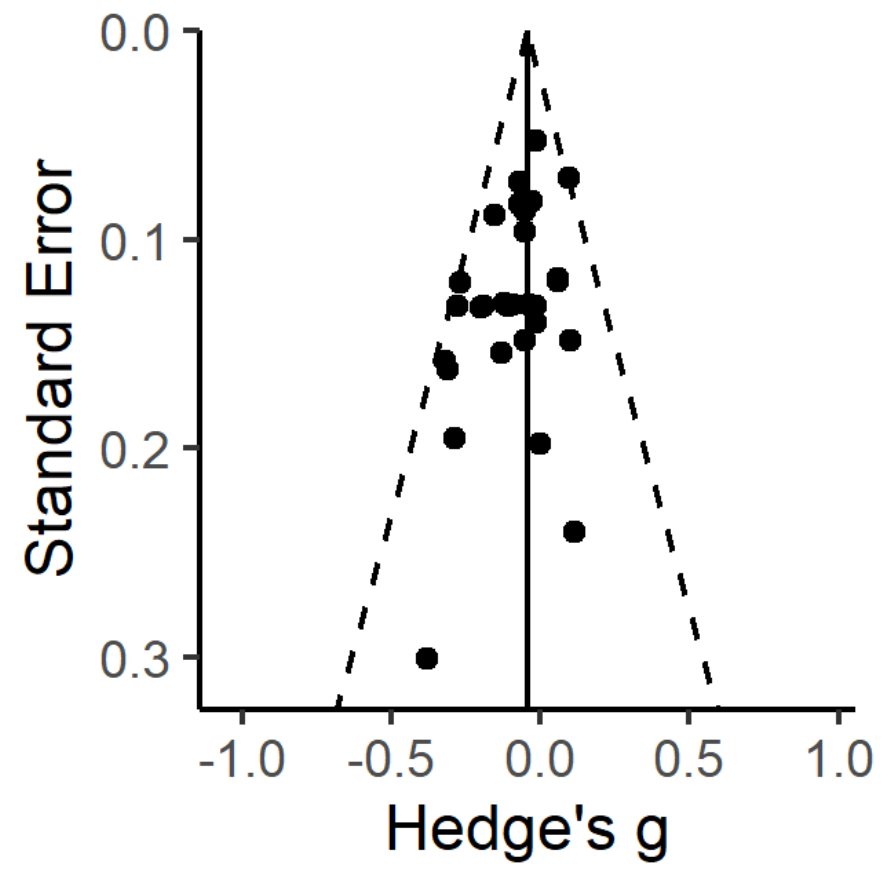


Appendix A. Full Search Syntax

AB ( "body dissatisfaction" OR "eating disorder" OR "anorexia nervosa" OR "bulimia nervosa" OR "binge eating disorder" OR "purging disorder" OR thin OR dieting OR diet OR "body image" OR "body acceptance") AND AB ( students OR youth OR adolescents OR teen OR children OR kids ) AND AB ( "randomized trial" OR program OR intervention OR treatment OR prevention OR rct OR "randomized control trial" OR "randomized clinical trial" ) AND TX (depression OR "depressive symptoms" OR "depression symptoms" OR "negative affect" ) NOT AB ( college OR university OR "post secondary" OR postsecondary ) NOT TI ( review OR meta-analysis ) 